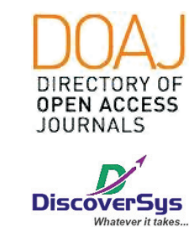

Published by DiscoverSys

\section{Gambaran kesehatan kerja pekerja bangunan di Kota Denpasar periode Agustus-Oktober 2017}

\author{
Faiz Afano, ${ }^{1 *}$ Putu Cintya Denny Yuliyatni, ${ }^{2}$ Luh Seri Ani ${ }^{2}$
}

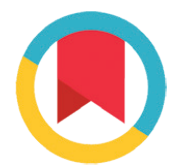

CrossMark

\title{
ABSTRACT
}

Background: Building construction is one of the most significant sectors related to the economic development in a country. However, the development of construction sector in Indonesia also has an impact in increasing problem regarding the occupational diseases, particularly among construction workers. In addition, construction workers require health insurance to facilitate the access to the nearest health center. Aim: The study aimed to describe the complaints of disease and behavior of accessing health facilities among construction workers in Denpasar city. Methods: This is a descriptive with cross-sectional research design which was implemented in Denpasar city among 101 subjects. The primary data was in the form of interview using questionnaire.
Results: The result revealed that all subjects were male. Majorities were $\leq 30$ years old, came from outside Bali, had worked for $\leq 5$ years, with duration of work $\leq 8$ hours, and in the light worker group. The construction workers mostly complained about lower back pain (34.4\%). A total of $63.4 \%$ of construction workers do not have health insurance, especially for workers who came from outside Bali.

Conclusion: Lower back pain tends to occur in workers from age group of $>30$ years, workers who work for $\leq 5$ years, workers with duration of work $>8$ hours, and in the heavy worker group. The tendency of ownership of health insurance in construction workers is not based on the length of work and the job field.

Keywords: pain complaints, insurance, construction workers

Cite This Article: Afano, F., Yuliyatni, P.C.D., Ani, L.S. 2020. Gambaran kesehatan kerja pekerja bangunan di Kota Denpasar periode AgustusOktober 2017. Intisari Sains Medis 11(2): 906-912. D01: 10.15562/ism.v11i2.231

\section{ABSTRAK}

Latar belakang: Konstruksi bangunan merupakan salah satu sektor yang sangat penting dalam perkembangan perekonomian suatu negara. Seiring dengan berkembangnya sektor pembangunan di Indonesia berdampak pula pada peningkatan masalah penyakit akibat kerja terutama pada pekerja bangunan. Selain itu pekerja bangunan memerlukan adanya jaminan kesehatan berupa asuransi untuk memudahkan akses ke fasilitas kesehatan terdekat.

Tujuan: Tujuan penelitian ini adalah untuk mengetahui gambaran keluhan penyakit dan perilaku mengakses fasilitas kesehatan pada pekerja bangunan di Kota Denpasar.

Metode: Jenis penelitian ini adalah deskriptif dengan pendekatan

1Program Studi Pendidikan Dokter, Fakultas Kedokteran, Universitas Udayana

${ }^{2}$ Bagian IImu Kedokteran Komunitas-IImu Kedokteran Pencegahan, Fakultas Kedokteran, Universitas Udayana

${ }^{*}$ Correspondence to: Faiz Afano, Program Studi Pendidikan Dokter, Fakultas Kedokteran, Universitas Udayana

faizafanoo@gmail.com

Diterima: 08-04-2018

Disetujui: $15-06-2018$

Diterbitkan: 01-08-2020

Kata kunci: keluhan sakit, asuransi, pekerja bangunan 2017. Intisari Sains Medis 11(2): 906-912. D0I: 10.15562/ism.v11i2.231

\section{PENDAHULUAN}

Konstruksi bangunan merupakan sektor yang penting dalam perkembangan perekonomian suatu negara. Namun, salah satu dampak sektor konstruksi bangunan adalah peningkatan masalah penyakit akibat kerja (PAK). Penyakit akibat kerja (PAK) didefinisikan sebagai semua penyakit yang

responden 101 orang. Penelitian ini menggunakan data primer berupa hasil wawancara menggunakan kuisioner.

Hasil: Dalam penelitian ini didapatkan hasil bahwa semua subyek penelitian adalah laki-laki. Mayoritas berusia $\leq 30$ tahun, berasal dari luar Bali, telah bekerja $\leq 5$ tahun, dengan durasi bekerja $\leq 8$ jam, dan bidang pekerjaan ringan. Keluhan yang paling banyak adalah nyeri punggung bawah (34.4\%). Sebanyak 63.4\% pekerja bangunan tidak memiliki asuransi kesehatan, terutama bagi pekerja yang berasal dari luar Bali.

Kesimpulan: Nyeri punggung bawah cenderung terjadi pada usia pekerja $>30$ tahun, pekerja yang bekerja selama $\leq 5$ tahun, pekerja dengan durasi kerja $>8$ jam, dan pada kelompok pekerja berat. Kecenderungan kepemilikan asuransi kesehatan pada pekerja bangunan tidak berdasarkan lama bekerja dan bidang pekerjaan.

Cite Pasal Ini: Afano, F., Yuliyatni, P.C.D., Ani, L.S. 2020. Gambaran kesehatan kerja pekerja bangunan di Kota Denpasar periode Agustus-Oktober

disebabkan karena paparan faktor risiko aktivitas pekerjaan. ${ }^{1}$

Keselamatan ketenagakerjaan di Indonesia diatur dalam Undang-Undang Nomor 23 Tahun 1992. Dalam UU tersebut disebutkan bahwa upaya kesehatan kerja wajib diselenggarakan pada 
setiap tenaga kerja, khususnya tempat kerja yang mempunyai risiko bahaya kesehatan yang besar bagi pekerja, agar dapat bekerja secara sehat tanpa membahayakan diri sendiri dan masyarakat sekelilingnya untuk memperoleh produktivitas kerja yang optimal sejalan dengan program perlindungan tenaga kerja. ${ }^{2}$ Hal ini juga didasarkan pada data International Labour Organization (ILO) yang menyatakan bahwa pada tahun 2013 ada lebih dari 250 juta kecelakaan di tempat kerja setiap tahun dan lebih dari 160 juta pekerja menjadi sakit karena bahaya di tempat kerja. Bahkan, 1,2 juta pekerja meninggal akibat kecelakaan di tempat kerja. ${ }^{3}$

Salah satu pekerjaan yang berisiko mengalami PAK adalah pekerja bangunan oleh karena berbagai faktor. Faktor-faktor tersebut diantaranya kondisi lingkungan berdebu, tempat tinggal yang tidak memadai, minimnya ketersediaan alat pelindung diri, dan keterbatasan akses fasilitas kesehatan. Berdasarkan survei dari The Center for Construction Research and Training, didapatkan data bahwa pekerja bangunan $30-40 \%$ mengalami nyeri kronis pada muskuloskeletal, 50\% mengalami gangguan pendengaran akibat bising, 5\% mengalami asbestosis, memiliki dua kali risiko untuk mengalami penyakit obstruksi paru, dan 50\% mengalami kanker paru meskipun bukan perokok. ${ }^{4}$ Keluhan penyakit tersebut menyebabkan gangguan dalam menjalani pekerjaan sehingga dapat menyebabkan penurunan kinerja pekerja bangunan.

Seiring dengan perkembangan sistem pelayanan kesehatan di Indonesia, tersedia pengobatan dengan sistem Jaminan Sosial Tenaga Kerja (Jamsostek). Jamsostek menurut UU Nomor 3 Tahun 1992 adalah suatu perlindungan bagi tenaga kerja dalam bentuk santunan berupa uang sebagai pengganti sebagian dari penghasilan yang dihilangkan atau berkurang dan pelayanan sebagai akibat peristiwa yang dialami oleh tenaga kerja, sakit, hamil, bersalin, hari tua, dan meninggal dunia. ${ }^{5}$ Saat ini, Jamsostek diimplementasikan oleh Badan Penyelenggara Jaminan Sosial (BPJS) Ketenagakerjaan yang bisa diakses oleh semua warga Indonesia. Hingga April 2016 peserta BPJS Ketenagakerjaan telah mencapai 12.892.318 peserta dan jumlah kasus yang telah tertangani mencapai 33.151 kasus. ${ }^{6}$

Bali merupakan salah satu provinsi dengan tingkat pembangunan yang pesat, terutama di Kota Denpasar. Hal ini dapat terlihat dari peningkatan intensitas pembangunan gedung perkantoran, pusat perbelanjaan, perumahan, institusi pendidikan, serta pariwisata. Pesatnya pembangunan di Kota Denpasar menyebabkan tingginya kebutuhan tenaga kerja, termasuk pekerja bangunan. Oleh sebab itu, diperlukan studi untuk mengetahui gambaran kesehatan kerja pekerja bangunan di Kota Denpasar agar dapat menjadi bahan rujukan perbaikan kesehatan kerja bagi pekerja bangunan di Kota Denpasar.

\section{METODE PENELITIAN}

Penelitian ini menggunakan rancangan deskriptif cross-sectional yang dilakukan di beberapa lokasi konstruksi bangunan di Kota Denpasar pada periode Agustus 2017-Oktober 2017. Jumlah sampel pada penelitian ini sebanyak 101 orang pekerja yang diambil melalui teknik non-probability sampling. Kriteria inklusi subjek penelitian adalah telah menjadi pekerja bangunan lebih dari 6 bulan serta bersedia menjadi responden dengan menandatangani informed consent.

Instrumen dalam penelitian ini menggunakan kuesioner yang terdiri dari karakteristik pekerja bangunan (umur, jenis kelamin, asal, lama bekerja, bidang pekerjaan), keluhan penyakit yang berhubungan dengan pekerja bangunan selama enam bulan terakhir, serta perilaku pekerja bangunan dalam mengakses fasilitas kesehatan (kepemilikan asuransi kesehatan, sumber pembiayaan kesehatan, dan kebiasaan pencarian layanan kesehatan).

Data yang diperoleh dalam penelitian berupa data deskriptif, kemudian dilakukan analisis menggunakan program komputer. Hasil pengolahan data tersebut kemudian dianalisis secara univariat dan bivariat untuk melihat gambaran keluhan penyakit dan perilaku mengakses fasilitas kesehatan pada pekerja bangunan.

\section{HASIL}

\section{Karakteristik Responden}

Dalam penelitian ini, rerata umur responden adalah 29,8 tahun dengan umur termuda adalah 19 tahun dan umur tertua adalah 52 tahun. Didapatkan responden berusia $<30$ tahun sebesar 54,5\% dan berusia diatas 30 tahun sebesar $45,5 \%$. Pekerja bangunan dalam penelitian ini 100\% adalah lakilaki dengan jumlah 101 orang. Pekerja bangunan yang berasal dari Bali sebanyak 21 orang $(20,8 \%)$ dan dari luar Bali sebanyak 80 orang (79,2\%). Para pekerja bangunan telah bekerja minimal 6 bulan dan maksimal 20 tahun dengan rata-rata durasi pekerajaan selama 6,9 tahun. Pekerja baru adalah pekerja yang bekerja $<5$ tahun, yakni sebanyak 55 orang $(54,5 \%)$, dan pekerja lama adalah pekerja yang bekerja $>5$ tahun sebanyak 46 orang $(45,5 \%)$. Rata-rata pekerja bangunan dalam 1 hari bekerja selama 8 jam. Sebanyak 95 pekerja bangunan $(94,1 \%)$ bekerja kurang dari 8 jam dan 6 orang $(5,9 \%)$ bekerja selama lebih dari 8 jam dalam sehari. Karakteristik demografis responden dapat dilihat pada Tabel 1. 


\section{Keluhan Pekerja}

Mayoritas keluhan penyakit pekerja bangunan adalah nyeri punggung bawah yaitu sebanyak 34 orang $(33,7 \%)$ dan paling sedikit adalah gangguan pendengaran. Distribusi keluhan pekerja bangunan dapat dilihat pada Tabel 2 .

\section{Perilaku Akses Kesehatan}

Berdasarkan Tabel 3, mayoritas pekerja bangunan tidak memiliki asuransi kesehatan (64 orang $[63,4 \%])$. Jenis asuransi kesehatan terbanyak adalah BPJS Kesehatan, yaitu sebanyak 25 orang $(24,8 \%)$, dan paling sedikit yaitu JKBM yang berjumlah 1 orang (1\%). Kepemilikan asuransi berpengaruh terhadap sumber pembiayaan kesehatan yang kebanyakan adalah melakukan pembiayaan sendiri (63 orang). Akses ke layanan kesehatan pekerja bangunan kebanyakan ke

Tabel 1 Distribusi proporsi pekerja bangunan berdasarkan karakteristik responden $(n=101)$

\begin{tabular}{|c|c|c|}
\hline Variabel & $\mathbf{N}$ & Frekuensi (\%) \\
\hline \multicolumn{3}{|l|}{ Umur (Tahun) } \\
\hline$<30$ tahun & 56 & 55,4 \\
\hline$>30$ tahun & 45 & 44,6 \\
\hline Median $\pm \mathrm{IQR}$ & \multicolumn{2}{|c|}{$30 \pm 12$} \\
\hline Min-Max & \multicolumn{2}{|c|}{$19-52$} \\
\hline Rerata & \multicolumn{2}{|c|}{29,8} \\
\hline \multicolumn{3}{|l|}{ Jenis Kelamin } \\
\hline Laki-Laki & 101 & 100 \\
\hline Perempuan & 0 & 0 \\
\hline \multicolumn{3}{|l|}{ Asal } \\
\hline Bali & 21 & 20,8 \\
\hline Luar Bali & 80 & 79,2 \\
\hline \multicolumn{3}{|l|}{ Lama Bekerja } \\
\hline Baru ( $\leq 5$ tahun $)$ & 55 & 54,5 \\
\hline Lama ( $>5$ tahun) & 46 & 45,5 \\
\hline Median \pm IQR & \multicolumn{2}{|c|}{$5 \pm 8$} \\
\hline Min-Max & \multicolumn{2}{|c|}{$1-20$} \\
\hline Rerata & \multicolumn{2}{|c|}{6,9} \\
\hline \multicolumn{3}{|l|}{ Durasi Bekerja } \\
\hline$\leq 8 \mathrm{jam}$ & 95 & 94,1 \\
\hline$>8 \mathrm{jam}$ & 6 & 5,9 \\
\hline Median $\pm \mathrm{IQR}$ & \multicolumn{2}{|c|}{$8 \pm 0$} \\
\hline Min-Max & \multicolumn{2}{|c|}{$7-11$} \\
\hline Rerata & \multicolumn{2}{|c|}{8,2} \\
\hline \multicolumn{3}{|l|}{ Bidang Pekerjaan } \\
\hline Berat & 32 & 31,7 \\
\hline Ringan & 69 & 68,3 \\
\hline
\end{tabular}

Min= Minimum, Max= Maksimum, IQR= InterQuartile Range puskesmas (45 orang) dan paling sedikit adalah ke rumah sakit (7 orang).

\section{Analisis Bivariat}

Pada analisis bivariat dikelompokkan keluhan nyeri punggung bawah dan keluhan lainnya karena nyeri punggung bawah paling banyak dikeluhkan oleh pekerja bangunan. Semakin tua umur pekerja bangunan, durasi bekerja yang lebih lama, dan bidang pekerjaan yang berat cenderung meningkatkan keluhan nyeri punggung bawah. Sebaliknya, semakin lama bekerja keluhan nyeri punggung bawah cenderung menurun (Tabel 4).

Selanjutnya, pekerja bangunan dengan asal daerah Bali lebih banyak memiliki asuransi kesehatan. Subyek dengan lama bekerja $\leq 5$ tahun dan bidang pekerjaan ringan cenderung lebih banyak yang memiliki asuransi kesehatan (Tabel 5).

\section{PEMBAHASAN}

\section{Distribusi Proporsi Pekerja Bangunan Berdasarkan Karakteristik Responden}

Berdasarkan Tabel 1, rerata umur pekerja bangunan adalah 29 tahun dengan rentang umur terbanyak adalah pada umur $<30$ tahun yaitu $55,4 \%$. Hal ini disebabkan karena banyak pekerja bangunan yang mencari peluang kerja lebih banyak pada kelompok usia produktif (19-30 tahun). Temuan ini sesuai dengan penelitian Tampinongkol, dkk (2016) yang menyatakan bahwa rentang umur dominan pekerja proyek konstruksi bangunan adalah 20-30 tahun sebesar $58,6 \%{ }^{7}$

Jenis kelamin pada penelitian ini adalah $100 \%$ laki-laki dimana selama melakukan penelitian peneliti tidak menemukan pekerja bangunan perempuan. Asal daerah pekerja bangunan mayoritas dari luar Bali yaitu sebanyak 80 orang $(79,2 \%)$ dan hanya 21 orang $(20,8 \%)$ saja yang berasal dari Bali. Hal ini mungkin bisa dijelaskan dari data Badan Pusat Statistika pada rentang tahun 20112017 yang menyebutkan bahwa tingkat pendidikan di Bali lebih tinggi dibandingkan provinsi di sekitar Bali (Jawa Timur, Nusa Tenggara Barat, Nusa Tenggara Timur). Hal tersebut secara tidak langsung berdampak pada lebih sedikitnya jumlah pekerja bangunan dari Bali. ${ }^{8}$

Pekerja bangunan pada penelitian ini memiliki rata-rata lama bekerja sebesar 6,9 tahun, dengan persentase terbesar berada pada rentang $<5$ tahun yaitu 54,5\%. Penelitian oleh Ahmad \& Budiman (2014) di Jakarta Utara mendapatkan hasil lama bekerja paling banyak adalah pada kelompok $<5$ tahun, yaitu sebanyak $64 \% .^{9}$ Hasil penelitian serupa juga disampaikan oleh Alghadir (2015) pada penelitiannya tentang prevalensi nyeri muskuloskeletatal pada pekerja bangunan di Arab Saudi 
Tabel 2 Distribusi proporsi keluhan sakit pekerja bangunan $(n=101)$

\begin{tabular}{lcc}
\hline Variabel & N & Frekuensi (\%) \\
\hline Nyeri Punggung Bawah & 34 & 33,7 \\
Gangguan Pendengaran & 7 & 6,7 \\
Sesak nafas & 20 & 19,8 \\
Iritasi Kulit & 17 & 16,8 \\
Trauma & 13 & 12,9 \\
Lainnya & 10 & 9,9 \\
\hline
\end{tabular}

Tabel 3 Distribusi proporsi perilaku mengakses fasilitas kesehatan $(n=101)$

\begin{tabular}{lcc}
\hline Variabel & N & Frekuensi (\%) \\
\hline Kepemilikan Asuransi & & \\
$\quad$ Punya & 37 & 36,6 \\
$\quad$ Tidak punya & 64 & 63,4 \\
Jenis Ansuransi & & \\
$\quad$ BPJS Kesehatan & 25 & 24,8 \\
BPJS Ketenagakerjaan & 4 & 4,0 \\
JKBM & 1 & 1 \\
Asuransi Swasta & 7 & 6,9 \\
Tidak Memiliki & 64 & 63,4 \\
Sumber Pembiayaan & & \\
Asuransi & 27 & 26,7 \\
Biaya Sendiri & 63 & 62,4 \\
Perusahaan & 11 & 10,9 \\
Akses Layanan Kesehatan & & \\
Puskesmas & 45 & 44,6 \\
Dokter Swasta & 16 & 15,8 \\
Klinik & 22 & 21,8 \\
Rumah Sakit & 7 & 6,9 \\
Pengobatan Sendiri & 11 & 10,9 \\
\hline
\end{tabular}

yaitu 51,2\% dari pekerja bangunan bekerja kurang dari 5 tahun. Hasil penelitian ini berkebalikan dengan penelitian Hasugian, dkk (2016) tentang penyakit akibat kerja di Kansashi Zhambia yang menyebutkan bahwa paling banyak lama bekerja yaitu 10 tahun sebesar 50\%. Hal ini kemungkinan disebabkan karena perbedaan karakteristik pada sampel penelitian yang diambil..$^{10,11}$

Durasi bekerja pekerja bangunan rata-rata adalah 8 jam (94,1\%). Lama kerja maksimal adalah 11 jam dalam sehari. Durasi bekerja tergantung dari kebijakan mandor atau jenis bangunan yang sedang dikerjakan. Pekerja bangunan yang sedang mengejar target selesainya pembangunan akan ditambahkan durasi bekerjanya. Namun, bagi mereka yang telah selesai mengerjakan target pembangunan akan diizinkan beristirahat terlebih dahulu (durasi bekerja berkurang). Penelitian oleh Ahmad \& Budiman (2014) mendapatkan hasil durasi kerja paling banyak adalah selama 4-6 jam dalam sehari. Hasil serupa juga disampaikan oleh Alazab (2004) pada pekerja bangunan di Mesir, dimana rata-rata durasi bekerja dalam sehari adalah 8 jam. Hasil berbeda didapatkan oleh Rinaldi, dkk (2015) dalam penelitiannya yang memperoleh hasil rata-rata durasi bekerja paling banyak adalah diatas 7 jam yaitu $55,8 \%{ }^{9}{ }^{912,13}$

Bidang pekerjaan yang ringan lebih besar persentasenya $(68,3 \%)$ dibandingkan yang bidang pekerjaannya berat $(31,7 \%)$. Bidang pekerjaan yang ringan meliputi mandor, tukang pembantu, tukang listrik, tukang cat, dan tukang kayu. Sedangkan bidang pekerjaan yang berat meliputi tukang gali, tukang besi, dan tukang besi. Berdasarkan penelitian oleh Fahmi, dkk (2014) di Garut, 67\% pekerja bangunan bekerja pada bidang pekerjaan ringan. Sedangkan temuan pada penelitian lain mendapatkan hasil 40\% pekerja bangunan bekerja di bidang pekerjaan ringan, yaitu sebagai mandor dan tukang pembantu (Sepang, dkk, 2013). Perbedaan persentase ini mungkin disebabkan karena perbedaan jenis bangunan yang dijadikan proyek. ${ }^{14,15}$

\section{Distribusi Proporsi Keluhan Sakit Pekerja Bangunan}

Berdasarkan Tabel 2, Keluhan sakit yang sering dikeluhkan oleh pekerja bangunan adalah nyeri punggung bawah yaitu sebesar $33,7 \%$. Penelitian yang dilakukan oleh Mohamed, dkk (2017) pada pekerja bangunan di kota Sherouk menyebutkan bahwa nyeri punggung bawah menjadi masalah kesehatan paling sering, yaitu sebesar 55\%. ${ }^{16}$ Wang, dkk (2017) dalam penelitiannya di Amerika menyatakan $40 \%$ dari pekerja bangunan mengeluhkan nyeri punggung oleh karena over exercise. ${ }^{17}$ Sedangkan keluhan lain adalah sesak napas sebesar $19,8 \%$, iritasi kulit $16,8 \%$, trauma $12,9 \%$, keluhan lainnya $9,9 \%$, dan gangguan pendengaran sebesar $6,9 \%$. Sesak napas dapat timbul akibat paparan asap dan debu pada pekerja bangunan, sedangkan keluhan iritasi kulit dapat ditimbulkan dari kontak langsung dengan bahan iritan seperti semen, cat, dan kayu yang mengandung potasium dichromate yang mudah mengiritasi dan menyababkan keluhan gatal atau panas pada kulit. ${ }^{18}$ Kesalahan menggunakan alat bangunan seperti gergaji, gerinda, dan alat pemotong juga berisiko untuk menyebabkan trauma luka pada pekerja bangunan. ${ }^{19}$ Keluhan yang paling sedikit ditimbulkan adalah gangguan pendengaran.

Paparan bising pada pekerja bangunan dapat ditimbulkan dari bunyi mesin yang digunakan selama bekerja maupun bunyi kendaraan yang berlalu lalang pada proyek pekerjaan. Paparan 
Tabel 4 Analisis bivariat gambaran umur, lama bekerja, durasi bekerja, bidang pekerjaan dengan keluhan penyakit $(n=101)$

\begin{tabular}{|c|c|c|c|c|c|c|c|}
\hline \multirow[b]{3}{*}{ Variabel } & & \multicolumn{4}{|c|}{ Keluhan penyakit } & & \\
\hline & & \multicolumn{2}{|c|}{ Nyeri punggung bawah } & \multicolumn{2}{|c|}{ Keluhan lainnya } & \multicolumn{2}{|c|}{ Total } \\
\hline & & $\mathbf{n}$ & (\%) & $\mathbf{n}$ & (\%) & $\mathbf{N}$ & $(\%)$ \\
\hline \multirow[t]{2}{*}{ Umur } & $<30$ tahun & 18 & 32,1 & 38 & 67,9 & 56 & $(100)$ \\
\hline & $>30$ tahun & 16 & 35,5 & 29 & 64,4 & 45 & $(100)$ \\
\hline \multirow[t]{2}{*}{ Lama bekerja } & $<5$ tahun & 25 & 45,5 & 30 & 54,5 & 55 & $(100)$ \\
\hline & $>5$ tahun & 9 & 19,6 & 37 & 80,4 & 46 & $(100)$ \\
\hline \multirow[t]{2}{*}{ Durasi bekerja } & $\leq 8 \mathrm{jam}$ & 31 & 32,6 & 64 & 67,4 & 95 & $(100)$ \\
\hline & $>8$ jam & 3 & 50 & 3 & 50 & 6 & $(100)$ \\
\hline \multirow[t]{2}{*}{ Bidang Pekerjaan } & Berat & 13 & 40,6 & 19 & 59,4 & 32 & $(100)$ \\
\hline & Ringan & 21 & 30,4 & 48 & 69,6 & 69 & (100) \\
\hline
\end{tabular}

Tabel 5 Analisis bivariat gambaran asal daerah, lama bekerja, bidang pekerjaan dengan kepemilikan asuransi kesehatan $(n=101)$

\begin{tabular}{|c|c|c|c|c|c|c|c|}
\hline \multirow[b]{3}{*}{ Variabel } & & \multicolumn{4}{|c|}{ Kepemilikan asuransi } & & \\
\hline & & \multicolumn{2}{|c|}{ Punya } & \multicolumn{2}{|c|}{ Tidak punya } & \multicolumn{2}{|c|}{ Total } \\
\hline & & $\mathbf{n}$ & (\%) & $\mathbf{n}$ & (\%) & $\mathbf{N}$ & (\%) \\
\hline \multirow[t]{2}{*}{ Asal Daerah } & Bali & 8 & 38,1 & 13 & 61,9 & 21 & (100) \\
\hline & Luar Bali & 29 & 36,3 & 51 & 63,8 & 80 & (100) \\
\hline \multirow[t]{2}{*}{ Lama bekerja } & $<5$ tahun & 21 & 38,2 & 34 & 61,8 & 55 & (100) \\
\hline & $>5$ tahun & 16 & 34,8 & 30 & 65,2 & 46 & $(100)$ \\
\hline \multirow{2}{*}{ Bidang pekerjaan } & Ringan & 26 & 37,7 & 43 & 62,3 & 69 & (100) \\
\hline & Berat & 11 & 34,4 & 21 & 65,6 & 32 & (100) \\
\hline
\end{tabular}

bising $>85 \mathrm{~dB}$ dalam waktu 8 jam sehari atau 40 jam perminggu dapat mengakibatkan gangguan pendengaran. ${ }^{20}$ Pada penelitian ini, peneliti tidak mencari detail dari faktor risiko terhadap keluhan ini.

\section{Distribusi Proporsi Perilaku Mengakses Fasilitas Kesehatan}

Berdasarkan Tabel 3, sebanyak 64 orang $(63,4 \%)$ pekerja bangunan tidak memiliki asuransi kesehatan, atau hanya 37 orang $(36,6 \%)$ yang memiliki asuransi kesehatan. Hal ini kemungkinan disebabkan karena rendahnya pengetahuan pekerja bangunan terhadap pentingnya asuransi kesehatan. Hasil ini sesuai dengan penelitian yang dilakukan oleh Tanjung (2015) di Lampung yang menyatakan bahwa secara statistik ada hubungan antara pengetahuan, sikap, informasi terhadap pemanfaatan Jaminan Kesehatan Nasional termasuk BPJS di dalamnya. ${ }^{21}$ Jenis asuransi yang paling banyak dipakai oleh pekerja bangunan adalah BPJS Kesehatan yaitu sebesar 24,8\%. Angka ini terbilang kecil jika dibandingkan dengan persentase peserta BPJS Kesehatan secara nasional, dimana pada tahun
2017 mencapai angka 70\% dari total penduduk Indonesia. ${ }^{22}$

Sumber pembiayaan kesehatan pada penelitian ini paling banyak menggunakan biaya sendiri $(62,4 \%)$, karena yang tidak memiliki asuransi kesehatan lebih besar daripada yang memiliki asuransi. Dari pekerja bangunan yang memiliki asuransi kesehatan, tidak semuanya dibiayai oleh asuransi karena 11 orang $(10,9 \%)$ dibiayai oleh perusahaan tempat mereka bekerja. Pemilik asuransi yang murni memakai pembiayaan kesehatan ketika sakit hanya 27 orang $(26,7 \%)$. Perusahaan konstruksi sebaiknya memperhatikan kesehatan para pekerja bangunan karena pemerintah sudah mengatur hal ini dalam Peraturan Pemerintah Nomor 29 Tahun 2000 tentang penyelenggaraan jasa konstruksi pasal 22 ayat (2) huruf b angka 4 yang menyatakan bahwa pertanggungan atau jaminan yang merupakan bentuk perlindungan dapat berupa antara lain asuransi atau jaminan yang diterbitkan oleh bank atau lembaga bukan bank. ${ }^{23}$

Akses layanan kesehatan bagi pekerja bangunan ketika sakit paling banyak adalah ke puskesmas, yaitu 45 orang $(44,6 \%)$. Hal ini disebabkan karena 
akses ke puskesmas yang mudah dan biaya pengobatan yang relatif murah dibandingkan rumah sakit dan klinik. Penelitian yang dilakukan oleh Wulandari (2016) tentang hubungan beberapa faktor keikutsertaaan BPJS kesehatan pada pekerja kelompok tani di Kabupaten Demak melaporkan bahwa 8 dari 10 responden memilih berobat ke puskesmas ketika sakit. ${ }^{24}$

\section{Kecenderungan Keluhan Sakit dan Kepemilikan Asuransi Berdasarkan Karakteristik Pekerja Bangunan}

Peneliti mengelompokkan keluhan dalam bekerja menjadi 2 kelompok besar dengan memfokuskan gejala nyeri punggung bawah terhadap faktor risiko yang ada selama bekerja. Peneliti memfokuskan pada nyeri punggung bawah dikarenakan prevalensi dari keluhan tersebut paling banyak dibandingkan keluhan yang lain (34,3\%). Berdasarkan Tabel 4, pekerja bangunan yang menderita nyeri punggung mayoritas berasal dari kelompok usia $>30$ tahun $(35,5 \%)$. Hasil temuan ini sesuai dengan hasil temuan Nurzanah, dkk (2015) dimana didapatkan peningkatan risiko nyeri punggung bawah pada kelompok usia 26-65 tahun ( $p$ value $=0.021$; $\mathrm{OR}=0.259$ ) yang dapat terjadi karena kemampuan fisik maksimal sesorang dicapai pada usia 25-40 tahun. Pada usia lebih dari itu kondisi fisik akan menurun dan menyebabkan penurunan ketahanan otot terhadap beban kerja, sehingga nyeri punggung bawah akan lebih mudah terjadi. ${ }^{25}$ Menurut penelitian yang dilakukan oleh Saputra (2010) tentang kejadian nyeri punggung bawah pada petani sawit di Kecamatan Dayun Kabupaten Siak, diperoleh hasil bahwa nyeri punggung terjadi pada rentang usia 31-40 tahun. Hal ini dikarenakan nyeri punggung bawah dipengaruhi oleh stres mekanis pada diskus vertebralis, yang risikonya semakin meningkat pada usia tua. Munculnya hasil yang sedikit berbeda ini mungkin dikarenakan perbedaan cut off point kelompok umur pada penelitian ini dan penelitian lainnya. ${ }^{26}$

Selain itu pekerja bangunan juga kebanyakan bekerja selama $<5$ tahun $(54,5 \%)$ dengan presentase yang lebih besar dibandingkan pekerja yang sudah bekerja $>5$ tahun. Hal ini berbeda dengan hasil penelitian Sianturi, dkk (2015), dimana ditemukan bahwa pekerja yang bekerja selama lebih dari 14 tahun cenderung lebih sering mengalami keluhan nyeri punggung bawah, walaupun hasil ini tidak memiliki perbedaan yang signifikan secara statistik ( $p$ value $=1.00$ ). Perbedaan hasil ini bukanlah sesuatu yang pasti mengingat sampel paling besar dalam penelitian ini berada pada rentang lama bekerja kurang dari 5 tahun. Hal ini juga mungkin terjadi karena tubuh pekerja yang sudah beradaptasi dengan baik saat melakukan pekerjaan yang sama selama lebih dari 5 tahun.
Durasi kerja yang lebih banyak menyebabkan nyeri punggung adalah $>8 \mathrm{jam}(50 \%)$. Hasil temuan ini sesuai dengan temuan Nurzanah, dkk (2015) dimana mereka menemukan bahwa pekerja dengan durasi kerja yang lebih lama cenderung memiliki keluhan nyeri punggung bawah ( $p$ value $=0.019$; $\mathrm{OR}=0.247)$. Hal ini dapat dijelaskan bahwa bekerja melebihi 8 jam tanpa beristirahat akan menyebabkan penurunan kemampuan tubuh dalam mempertahankan kontraksi statis otot sehingga akan menimbulkan nyeri. ${ }^{25}$

Nyeri punggung juga lebih banyak terjadi pada kelompok pekerjaan berat $(40,6 \%)$. Hasil penelitian ini sesuai dengan hasil penelitian Nurzanah, dkk (2015), dimana ditemukan adanya korelasi signifikan antara beban kerja dan keluhan nyeri punggung bawah ( $p$ value $=0.042 ; \quad \mathrm{OR}=0.304$ ), dimana beban kerja yang tinggi memiliki kecenderungan untuk memiliki nyeri punggung bawah. Hal ini terjadi karena selama terjadi kontraksi otot statis pada beban kerja yang berat, pembuluh darah tertekan oleh jaringan otot sehingga sirkulasi darah ke otot menjadi terhambat dan menimbulkan nyeri. ${ }^{25}$ Hal ini bertolak belakang dengan temuan pada penelitian lain. Pada penelitian yang dilakukan Setiawan (2015), tingkat beban kerja yang tinggi tidak memiliki korelasi dengan keluhan nyeri punggung ( $p$ value $=1.00) .{ }^{27}$ Perbedaan hasil penelitian ini dapat disebabkan oleh perbedaan jumlah sampel, serta kesubjektifan peneliti maupun responden dalam mengklasifikasikan beban kerja yang berat dan ringan.

Berdasarkan Tabel 5, pekerja bangunan yang berasal dari Bali memiliki persentase kepemilikan asuransi kesehatan lebih tinggi $(38,1 \%)$. Hal ini disebabkan oleh sistem BPJS yeng menerapkan pelayanan kesehatan tujuan adalah sesuai dengan domisili tempat tinggal. Selain itu, sebagian dari pekerja bangunan yang berasal dari luar Bali tidak memiliki KIPEM (Kartu Identitas Penduduk Musiman), sehingga menyebabkan kesulitan dalam mengurus asuransi khususnya BPJS. Oleh karena itu, sebaiknya para pekerja bangunan memiliki identitas berupa KIPEM agar memudahkan dalam mengurus BPJS di wilayah Denpasar.

Pekerja bangunan dengan lama bekerja $\leq 5$ tahun memiliki persentase kepemilikan asuransi kesehatan lebih tinggi dibandingkan dengan yang telah bekerja $>5$ tahun. Bidang pekerjaan ringan memiliki persentase kepemilikan asuransi yang lebih tinggi (37,6\%) dibandingkan dengan bidang pekerjaan berat. Hasil ini belum dapat dibandingkan dengan penelitian lain karena belum ada penelitian yang dipublikasi terkait kepemilikan asuransi dan bidang pekerjaan. Dari hasil ini bisa diasumsikan bahwa kecenderungan kepemilikan asuransi tidak berdasarkan lama bekerja dan bidang pekerjaan, 
namun ada faktor lain yang mungkin tidak diteliti dalam penelitian ini.

Keterbatasan dalam penelitian ini adalah dalam pengukuran tentang bidang pekerjaan dimana responden hanya memilih satu bidang pekerjaan dominan sementara seringkali mereka mengerjakan beberapa bidang sekaligus. Hal ini dapat berpengaruh pada hasil penelitian. Selain itu dalam penelitian ini hanya menemukan pekerja bangunan laki-laki, sehingga hasil dari penelitian ini hanya mengetahui gambaran kesehatan pekerja bangunan laki-laki.

\section{SIMPULAN}

Pekerja bangunan di kota Denpasar paling banyak mengeluhkan nyeri punggung bawah $(34,4 \%)$. Nyeri punggung bawah cenderung terjadi pada usia pekerja $>30$ tahun, pekerja yang bekerja selama $<5$ tahun, pekerja dengan durasi kerja $>8$ jam, dan pada kelompok pekerja berat. Sekitar $63,4 \%$ dari pekerja bangunan tidak memiliki asuransi kesehatan, terutama bagi pekerja yang berasal dari luar Bali. Kecenderungan kepemilikan asuransi kesehatan pada pekerja bangunan tidak berdasarkan lama bekerja dan bidang pekerjaan.

\section{DAFTAR PUSTAKA}

1. Workplace Safety and Health Council. Safety and health guidelines diagnosis and management of occupational diseases [Internet]; 2011 [Diakses pada tanggal 25 Januari 2017]. Tersedia pada: www.wshc.sg

2. Undang-Undang Republik Indonesia Nomor 23 Tahun 1992 tentang Kesehatan; 1992.

3. Internatioal Labour Organization. Keselamatan dan kesehatan kerja sarana untuk produktivitas. Jakarta; 2013.

4. The Center for Construction Research and Training. Occupational disease among construction workers [Internet]; 2012 [Diakses pada tanggal 25 Januari 2017]. Tersedia pada: www.cpwr.com/sites/default/files

5. Jaminan Sosial Indonesia. JAMSOSTEK [Internet]; 2015 [Diakses pada tanggal 28 Januari 2017]. Tersedia pada: www.jamsosindonesia.com/jamsostek

6. BPJS Ketenagakerjaan. Panduan jaminan sosial ketenagakerjaan bagi peserta [Internet]; 2014 [Diakses pada tanggal 28 Januari 2017]. Tersedia pada: www.bpjsketenagarkerjaan.go.id

7. Tampinongkol I, Diana VD, Doda, Kaunang WPJ. Hubungan antara penggunaan alat pelindung diri dengan kejadian kecelakaan kerja pada pekerja proyek konstruksi pembangunan gedung baru Fakultas Kedokteran Universitas Sam Ratulangi Manado. Jurnal Ikmas. 2016;1(5):1-8.

8. Badan Pusat Statistika Nasional. Angka partisipasi kasar menurut provinsi [Internet]; 2017 [Diakses pada tanggal 27 Januari 2017]. Tersedia pada: https://www.bps.go.id/ dynamictable/2015/12/22/1050/angka-partisipasi-kasarapk-menurut-provinsi-2011-2017.html.

9. Ahmad A, Budiman F. Hubungan posisi duduk dengan nyeri punggung bawah pada penjahit vermak levis di Pasar Tanah Pasir Kelurahan Penjaringan Jakarta Utara tahun 2014. Forum Ilmiah. 2014;11(3):412-420.
10. Alghadir A. Prevalence of musculoskeletal pain in construction workers in Saudi Arabia. The Scientific World Journal. 2015;2015:1-5.

11. Hasugian AR. Perilaku pencegahan penyakit akibat kerja tenaga kerja Indonesia di Kansashi, Zambia: Analisis Kualitatif. Media Penelitian dan Pengembangan Kesehatan. 2017;27(2):111-124.

12. Alazab RMA. Work-related disease and occupational injuries among workers in the construction industry. African Newsletter on Occupational Health and Safety. 2004;14:37-42.

13. Rinaldi E, Utomo W, Nauli FA. Hubungan posisi kerja pada pekerja industri batu bata dengan kejadian low back pain. JOM. 2015;2(2):1085-1093.

14. Fahmi NA, Farida I, Ismail A. Analisis manajemen risiko kesehatan dan keselamatan kerja (k3) pada pekerjaan upper structure gedung bertingkat. Jurnal Konstruksi Sekolah Tinggi Teknologi Garut. 2014;13(1):1-13.

15. Sepang BAW, Tjakra J, Langi EC, Walangitan DRO. Manajemen risiko keselamatan dan kesehatan kerja (K3) pada proyek pembangunan ruko orlens fashion Manado. Jurnal Sipil Statik. 2013;1(4):282-288.

16. Mohamed HAK. Occupational hazards and their relation with health problems among construction building workers at El Sherouk City. American Journal of Nursing Research. 2017;5(3):96-103.

17. Wang $\mathrm{X}$, et al. Work-related musculoskeletal disorders among construction workers in the United States from 1992 to 2014. Occupational of Environmental Medicine. 2017;74:374-380.

18. Purnamasari IAD, Rusyanti LM, Darmada IGK. Dermatitis kontak pada pekerja bangunan. Denpasar. Medika Udayana; 2013.

19. Barss P, et al. Occupational injury in the United Arab Emirates: epidemiology and prevention. Occupational Medicine. 2009;59:493-498.

20. Kementrian Kesehatan Republik Indonesia. Pedoman tatalaksana penyakit akibat kerja bagi petugas kesehatan: Penyakit THT Akibat Kerja. Jakarta; 2011.

21. Tanjung FF. Analisis faktor-faktor yang mempengaruhi pemanfaatan program Jaminan Kesehatan Nasional (JKN) di balai pengobatan Imam Bonjol Bandar Lampung. Bandar Lampung: Universitas Lampung; 2015.

22. BPJS Kesehatan. BPJS Kesehatan [Internet]. 2017 [Diakses pada tanggal 9 Januari 2017]. Tersedia pada: https:// bpjs-kesehatan.go.id

23. Pemerintah Indonesia. Peraturan Pemerintah Republik Indonesia (PP) Nomor 29 Tahun 2000 (29/2000) Tentang Penyelenggaraan Jasa Konstruksi: Jakarta; 2000.

24. Diah WL. Hubungan antara beberapa faktor dengan keikutsertaan BPJS kesehatan pada pekerja kelompok tani sektor informal profesi petani di Desa Cabean Kecamatan Wonosalam Kabupaten Demak Tahun 2016. Semarang: Universitas Dian Nuswantor; 2016.

25. Nurzannah, Sinaga M, Salmah U. Hubungan faktor resiko dengan terjadinya nyeri punggung bawah pada tenaga kerja bongkar muat di Pelabuhan Belawan Medan tahun 2015. Jurnal Penelitian Kesehatan Masyarakat; 2015.

26. Saputra B. Hubungan posisi kerja terhadap kejadian low back pain pada petani sawit di kecamatan Dayun kabupaten Siak. Pekanbaru; 2010.

27. Setiawan H. Desain lingkungan kerja industri karet berbasis ergonomi guna reduksi beban kerja dan peningkatan produktivitas. Jurnal Ilmiah Tekno. 2015;7(1):29-37.

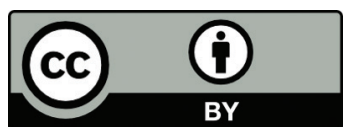

This work is licensed under a Creative Commons Attribution 